\title{
MANAJEMEN SUPERVISI KLINIS UNTUK MENINGKATKANPROFESIONALISME GURU DI SEKOLAH MENENGAH ATAS KOLESE DE BRITTO YOGYAKARTA
}

\author{
YohanesUmbuLede, M. Pd \\ Program Studi Pendidikan Keagamaan Katolik, Sekolah Tinggi Keguruan dan Ilmu \\ Pendidikan Weetebula
}

*Corresponding Author: Umbu Lede, Y, Program Studi Pendidikan Keagamaan Katolik, Sekolah Tinggi Keguruan dan Ilmu Pendidikan Weetebula; Email: yantoumbu071@gmail .com

\begin{abstract}
The research aimed to know the clinical supervission management to improve teacher's professionalism in Senior High School of Kolese De Britto Yogyakarta.

This research was conducted in Senior High School of Kolese De Britto Yogyakarta. The collecting data method were interview, observation and documentation. The informan in this research wereprincipal, teachers and supervisor. The data validity were done by triangulation techniques. The data were analyzed by interactive analysis model.

Results of the research showed that: (1) Clinical supervision management to improve teachers professionalism in Senior High School of Kolese De Britto Yogyakarta was successful. Supervission management in grew continuously and systematically. Supervisors understand and know about clinical supervision properly, help and guidance teachers with aims for learning emendation. (2) Professional competence of teachers which felt needs to understood and well known at Senior High School Kolese De Britto are competences of professional teachers based on vision and mission in school. The competences mentioned is suitable with school vision and mission based on leadership competence. (3) Senior High School Kolese De Britto as educational institutions, support Ignatian spirituality. The term of this spiritual is risen from the knowledge about contexts, action, reflection, and evaluation. The learning quality is not only just about transfer of knowledge, but also aboutvalues. (4) Supporting factors in the management of clinical supervisioninclude a culture and school management, initiative and transparency of a teacher, and human resources that support, institution staffs and foundation give PKG and FDG socialization, and evaluation activities. (5) Constraints factors in implementation of clinical supervision management are: erroneous paradigms about clinical supervision (supervision is still looked and understood as an assessment for a teacher performance), time for teaching is demanding schedule, there are unnatural situation and action in the class, there are some teachers don't have openhanded when under strict, there are psychology constraint, and achievable of using technology based on IT.
\end{abstract}

Keywords: Clinical Supervision, Teacher Professionalism. 


\section{Pendahuluan}

Keberhasilan pendidikan dipengaruhi oleh berbagai unsur seperti: guru, siswa, pengelolaan dan pembiayaan. Unsur-unsur tersebut sangat berperan penting dalam menentukan keberhasilan pendidikanataumutu. Diharapkan unsur-unsur tersebut saling menopang satu sama lain. Dalam konteks pendidikan terutama untuk meningkatkan kualitas pendidikan, unsur yang sangat berperan adalah guru.

Guru sebagai pelaku utama dalam proses pendidikan hendaknya diberi bantuan, dinilai, dievaluasi (disupervisi) dalam konteks bukan untuk mencari-cari kesalahan atau kekurangan. Guru hendaknya mendapat perhatian dari pengawas sekolah, kepala sekolah atau pihak lain yang berwenang dalam mengevaluasi guru (supervisor). Kepala sekolah atau pihak yang berwenang melakukan supervisi demi mendukung kinerja guru untuk meningkatkan kualitas pendidikan. Guru perlu disupervisi sehingga melalui kegiatan ini mereka menyadari bahwa kinerja mereka hendaknya diperbaiki dan akhirnya berjalan sesuai dengan apa yang menjadi harapan pemerintah yaitu melahirkan generasi baru yang unggul dalam segi pengetahuan, kreatifitas dan karakter.

Realitas yang terjadi selama ini bahwa supervisi dipandang kurang penting dalam proses pendidikan. Supervisi dilakukan hanya semata-mata formalitas dan bukannya timbul dari kesadaran individual akan pentingnya supervisi demi meningkatkan mutu pendidikan dalam konteks pembangunan manusia secara utuh dan menyeluruh. Tak jarang kita menemukan ada kegiatan supervisi hanya dipandang perlu untuk dilakukan jika dalam konteks mendesak atau karena tuntutan dari pihak atasan (pemerintah). Substansi dan tujuan utama dari supervisi menjadi hilang dan tidak dimaknai secara baik oleh hampir sebagian besar pihak yang berkecimpung dalam dunia pendidikan (Barinto dalam Jurnal Tabularasa PPS UNIMED Vol.9 No.2, Desember 2012).

\section{Metode Penelitian}

Jenispenelitianiniadalahpenelitiankualitatif,

dilaksanakan di SMA Kolese De Britto Yogyakarta.Pelaksanaan penelitian ini dilaksanakan pada semester II TahunAjaran 2014/2015.Sumber data dalam penelitian ini adalahinforman yang meliputikepalasekolah, guru dan supervisor. Sumber data yang lain adalah tempat, kegiatan dan peristiwasertadokumen yang berkaitandengankegiatansupervisiterhadap guru. Teknik pengumpulan data meliputi observasi, wawancara mendalam, dan dokumentasi.Teknik trianggulasi juga digunakan dalam penelitian ini. Data yang sudah terkumpul dalam penelitian ini kemudian dianalisis berdasarkan model analisis interaktif yang meliputikeabsahan data, reduksi data, display data, dan penarikan kesimpulanatauverifikasi.

\section{Hasil Penelitiandan Pembahasan}

\section{Manajemen Supervisi Klinis di Sekolah Menengah Atas Kolese De Britto Yogyakarta.} Pelaksanaan supervisi klinis di SMA Kolese De Britto mengalami perkembangan yang cukup baik dari tahun ke tahun. Hal ini dapat diketahui melalui penanganan dan pemahaman yang lebih baik dan benar oleh para supervisor. Supervisi klinis tidak dipahami lagi sebagai bentuk penilaian terhadap guru. Kegiatan dan jadwal supervisi klinis direncanakan dengan baik dan hal ini 
Lede, Jurnal Edukasi Sumba (JES), 2020 (4) 2 : 96-102

nampak dalam pembentukan tim supervisi yang berjumlah 8 orang dan pengaturan jadwal yang tetap. Konsep supervisi klinis yang dipahami oleh supervisor adalah supervisi yang difokuskan pada pemberian bantuan dan pendampingan terhadap guru demi perbaikan pembelajaran melalui tahap yang sistematis mulai dari tahap pertemuan awal (pre-observation), pengamatan (observation) dan pertemuan pasca-observasi (post-observation) terhadap proses pembelajaran yang terjadi dengan tujuan untuk memperbaiki proses pembelajaran.

Realitastersebutsejalandengan tujuan supervisi klinis yang dimaksudkan untuk: menciptakan kesadaran guru tentang tanggung jawabnya terhadap pelaksanaan kualitas proses pembelajaran, membantu guru untuk senantiasa memperbaiki dan meningkatkan kualitas proses pembelajaran, membantu guru untuk dapat mengidentifikasi dan menganalisis masalah yang muncul dalam proses pembelajaran, membantu guru untuk dapat menemukan cara pemecahan masalah yang ditemukan dalam proses pembelajaran dan membantu guru mengembangkan sikap positif dalam mengembangkan diri secara berkelanjutan (Kursus Kepemimpinan Sekolah, 2009, Supervisi Di Sekolah, hal: 49). Model supervisi yang digunakan di SMA Kolese De Britto ada dua yakni informal supervisi dan formal supervisi(Kursus Kepemimpinan Sekolah, 2009, Supervisi Di Sekolah, hal: 47-48).

2. Manajemen Supervisi Klinis di Sekolah Menengah Atas Kolese De Britto Yogyakarta Untuk Meningkatkan Profesionalisme Guru.

Kompetensi profesional guru yang dipandang
p-ISSN: 2549-8533

e-ISSN : 2714-8580

perlu dipahami dan diketahui dengan baik di SMA Kolese De Britto adalah kompetensi profesional guru. Adapun kompetensi yang dimaksudkan yang sesuai dengan visi misi sekolah adalah kompetensi leadership. Guru harus memiliki kemampuan leadership yang total dan unggul. SMA Kolese De Britto mengembangkan spiritualitas Ignasian sehingga harus diukur juga instrumen-instrumen dalam menilai guru. Guru dikatakanprofesional di SMA De Britto yakniguru yang mempunyai kompetensi spiritual dan leadership serta kompetensi pedagogis dan sosial serta kepribadian. Kompetensi yang dimiliki guru semuanya harus tampak di sekolah dalam keseluruhan proses pembelajaran sehingga dapat dinilai secara obyektif.

Fakta tersebutsesuaidengankonsepbahwa guru profesional merupakanpribadi yang mampu melihat konteks dengan baik dan benar dalam keseluruhan proses pembelajaran di kelas. Guru mampu merefleksikan tema pembelajaran dan nilai penting apa yang ditawarkan kepada peserta didik dalam proses pembelajaran. Dengan demikian, yang terjadi bukanlah transfer of knowledge saja tetapi juga transfer of values. Guru profesional adalah guru pemimpin atau leadership terutama menjadi pemimpin bagi siswa dalam kegiatan pembelajaran di kelas. Selain itu juga, guru mampu menjadi instruction leadership (pemimpin pembelajaran). Pola pendekatan seorang guru profesional harus sesuai dengan konteks anak yang sedang dipimpin atau didampingi. Anak-anak zaman sekarang tidak mampu berpikir secara mendalam. Mereka harus terus-menerus dilatih untuk berpikir kritis. Guru 
Lede, Jurnal Edukasi Sumba (JES), 2020 (4) 2 : 96-102

harus benar-benar mempunyai teknik atau metode pendekatan yang on going formation artinya pendampingan lanjutan serta tidak puas dengan apa yang ada saat ini. Hal ini sejalan dengan pendapat Endang Komara, (2006:1) tentang guru adalah pendidik profesional dengan tugas utama mendidik, mengajar, membimbing, mengarahkan, melatih, menilai, dan mengevaluasi peserta didik. Peserta didik diarahkan tidak saja mampu dari segi intelektual tetapi mereka juga diinternalisasikan nilai-nilai hidup seperti disiplin, toleransi, tanggung jawab, kejujuran, tanggung jawab dan keterbukaan. Peran guru akan menjadi sangat penting dalam proses ini.

\section{Faktor-Faktor yang Mendukung Pelaksanaan} Manajemen Supervisi Klinis di Sekolah Menengah Atas Kolese De Britto Yogyakarta.

Dalam pelaksanaan manajemen supervisi klinis ada beberapa faktor pendukung sehingga kegiatan supervisi pembelajaran dapat berjalan dengan baik. Faktor-faktor tersebut antara lain: Pertama, kultur dan manajemen sekolah. Kultur yang baik hendaknya dibangun atau diciptakan oleh setiap unsur yang ada di sekolah sehingga yang diharapkan dapat tercapai dalam proses supervisi klinis. Selain kultur yang baik yang dibangun secara bersama, manajemen sekolah diharapkan dapat dijalankan dengan baik. Pemimpin pembelajaran atau kepala sekolah dapat mengorganisir setiap pelaksanaan kegiatan supervisi klinis sehingga mampu menumbuhkan pemahaman yang baik tentang supervisi dari setiap guru. Kedua, inisiatif dan keterbukaan mesti dimiliki oleh setiap guru yang hendak disupervisi. Keterbukaan dan inisiatif menjadi pintu masuk
p-ISSN: 2549-8533 e-ISSN : 2714-8580

bagi supervisor untuk memberikan bantuan bagi guru dalam meningkatkan keterampilan mengajar mereka. Ketiga, potensi atau sumber daya manusia yang menunjang. Ketersediaan sumber daya manusia yang mumpuni akan turut mendukung keberhasilan pelaksanaan manajemen supervisi klinis di sekolah. Pihak sekolah dalamhalini SMA Kolese De Britto terus meningkatkan kapasitas supervisor agar semakin berkompeten, terampil, dan unggul. Keempat, pihak sekolah dan yayasan mengadakan kegiatan pelatihan PKG (Pelatihan Kinerja Guru) dan FDG (Forum Diskusi Guru atau lebih dikenal MGMP) di sekolah melalui kerjasama dengan Dinas Pendidikan. Dan Kelima, pada akhir dari keseluruhan proses kegiatan supervisi klinis, tim supervisi sekolah melaksanakan proses evaluasi.

4. Faktor-Faktor Yang Menghambat Pelaksanaan Manajemen Supervisi Klinis Di Sekolah Menengah Atas Kolese De Britto Yogyakarta.

Ada beberapa hambatan yang ditemukan dalamkegiatansupervisiklinisdi SMA Kolese De Britto antara lain: Pertama, adanya paradigma yang keliru tentang supervisi klinis yakni supervisi masih dilihat dan dipahami sebagai bentuk penilaian terhadap kinerja seorang guru, Kedua, waktu untuk mengajar sangat banyak sehingga proses supervisi menjadi terhambat dan kadang tidak ada kesempatan bagi guru untuk disupervisi, Ketiga, adanya situasi dan tindakan yang tidak natural saat kegiatan supervisi dilaksanakan di dalam kelas.Keempat, dalam pelaksanaan kegiatan supervisi klinis di sekolah, tim masih menemukan adanya beberapa guru yang belum terbuka ketika disupervisi. Kelima, ada kendala-kendala psikologis yang ditemukan seperti cara pandang 
Lede, Jurnal Edukasi Sumba (JES), 2020 (4) 2 : 96-102

yang muncul antara supervisor (yang masih yunior) dan guru yang disupervisi (senior). Keenam, kemampuan

yang

belummemadaiterhadappenguasaan teknologi berbasis IT dalam proses pembelajaran menjadi faktor penghambat peningkatan mutu pembelajaran.

\section{Kesimpulan dan Saran}

\section{A. Kesimpulan}

1. Perencanaan manajemen supervise klinis di Sekolah Menengah Atas Kolese De Britto dilaksanakan dengan baik mulai dari tahapan perencanaan, pelaksanaan dan evaluasi. Konsep supervisi klinis yang dipahami dalam pelaksanaannya adalah supervisi yang difokuskan pada pendampingan terhadap guru demi perbaikan pembelajaran melalui tahap yang sistematis mulai dari tahap pertemuan awal (pre-observation), pengamatan (observation) dan pertemuan pasca-observasi (post-observation) terhadap proses pembelajaran yang terjadi dengan tujuan untuk memperbaiki proses pembelajaran.

2. Pelaksanaan supervise klinis dalam upaya meningkatkan profesionalisme guru di Sekolah Menengah Atas Kolese De Britto Yogyakarta, terutamapemahaman tentang kompetensi profesional guru mengacu pada visi dan misi sekolah. Kompetensi profesional lebih dikaitkan dengan kompetensi leadership dari seorang guru atau tenaga pendidik. Guru mampu mengorganisir kelas dalam proses belajar mengajar yang sedang berlangsung di kelas. Selain itu, guru mampu memotivasi peserta didik untuk belajar bukan saja tentang tentang pengetahuan tetapi juga nilai-nilai hidup (kedisiplinan, kerja sama, toleransi dan lain-lain).

Dalam kaitannya dengan supervisi klinis, salah satu aspek kompetensi pedagogis adalah transfer of values di sekolah dan bukan transfer of knowledge. Guru mampu menjadi instruction leadership (pemimpin pembelajaran). Guru harus benar-benar mempunyai teknik atau metode pendekatan yang on going formation artinya pendampingan lanjutan serta tidak puas dengan apa yang ada saat ini. Adapun teknikteknik peningkatan profesionalisme guru yang dilakukan di SMA Kolese De Britto yakni melalui bedah buku (lessons study), studi lanjut guru, induksi nilai-nilai untuk setiap guru baru dan kegiatan evaluasi yang diadakan di tingkat sekolah. Faktor-faktor yang penting ada dalam peningkatan profesionalisme guru yakni pertama, motivasi dari guru. Kedua, faktor relasi antara supervisor dengan yang disupervisi. Ketiga, tuntutan dari luar diri orang yang disupervisi.

3. Faktor-faktor pendukung yang sangat menentukan keberhasilan pelaksanaan manajemen supervisi klinis di sekolah ini. Adapun faktor-faktor pendukung yang dimaksud meliputi 5 (lima) macam yakni sebagai berikut: Pertama, kultur dan manajemen sekolah. Kultur sekolah hendaknya mempunyai respek terhadap sesama, sehingga supervisi klinis dapat 
Lede, Jurnal Edukasi Sumba (JES), 2020 (4) 2 : 96-102

berjalan dengan baik. Selanjutnya peran manajemen sekolah dilihat dari sejauh mana pemimpin sekolah atau pememimpin pembelajaran (kepala sekolah) mampu mengorganisir guru.

Manajemen supervisi akan menumbuhkan pemahaman guru tentang supervisi dalam peningkatan profesionalisme guru, peningkatan mutu pembelajaran, dan pengelolaan kelas. Kedua, ada inisiatif dan keterbukaan dari pihak guru untuk disupervisi. Inisiatif dan keterbukaan ini mendorong supervisor untuk memberikan input terhadap kendala yang dialami oleh orang yang disupervisi. Ketiga, sumber daya manusia yang sangat menunjang. Ketersediaan sumber daya manusia yang berkompeten, terampil dan unggul sangat mendukung pelaksanaan kegiatan supervisi klinis. Keempat, pihak sekolah dan yayasan mengadakan kegiatan pelatihan PKG dan FDG di sekolah melalui kerjasama dengan Dinas Pendidikan atau pihak terkait. Kelima, Pada akhir dari keseluruhan proses kegiatan supervisi klinis, tim supervisi sekolah melaksanakan proses evaluasi.

4. Faktor-faktor yang menjadi kendala dalam pelaksanaan manajemen supervise klinis di Sekolah Menengah Atas Kolese De Britto Yogyakarta. Pertama, masih terdapat sebagian guru yang mempunyai paradigma yang keliru tentang supervisi klinis yakni supervisi masih dilihat dan dipahami sebagai bentuk penilaian terhadap kinerja seorang guru.Kedua, waktu untuk mengajar
p-ISSN: 2549-8533

sangat banyak sehingga proses supervisi menjadi terhambat dan kadang tidak ada kesempatan bagi guru untuk disupervisi. Ketiga, masih terdapat situasi dan tindakan dari sebagian guru yang tidak natural saat kegiatan supervisi dilaksanakan di dalam kelas. Keempat,secara teori dan konsep serta keterampilan, tidak semua guru dan supervisor paham tentang supervisi klinis. Kelima, tim masih menemukan adanya beberapa guru yang belum terbuka ketika disupervisi. Keenam, ada kendala-kendala psikologis yang ditemukan seperti cara pandang yang muncul antara supervisor (masih yunior) dan guru yang disupervisi (senior).Ketujuh,minimnya penguasaan teknologi berbasis IT dalam proses pembelajaran.

\section{B. Saran}

1. Bagi Kepala Sekolah dan Supervisor:

a. Peningkatan pemahaman pada sebagian guru agar memiliki pemahaman yang benartentang supervisi klinis.

b. Supervisor atau tim supervise terus mengembangkan keterampilan supervisi.

c. Membantu guru yang disupervisi agar keterampilan mengajar guru dapat berkembang dari waktu kewaktu.

d. Tim supervise memahami dan mencermati model pencatatan dan pengisian format supervise dengan baik dan benar.

e. Kepala sekolah dan supervisor perlu menata kembali jadwal kegiatan supervise secara tepat agar guru mempunyai waktu untuk disupervisi dan tidak dan guru dapat 
Lede, Jurnal Edukasi Sumba (JES), 2020 (4) 2 : 96-102

bertindak secara natural dalam pelaksanaan kegiatan supervise klinis.

2. Bagi Guru

a. Guru disarankan agar dapat memahami keberadaan pelaksanaan manajemen supervise klinis sebagai bentuk bantuan untuk meningkatkan profesionalisme guru dan bukan sebagai bentuk penilaian kinerja guru.

b. Guru disarankan agar dapat bertindak secara natural dalam setiap pelaksanaan kegiatan supervisiklinis di sekolah.

c. Guru perlu membangun komunikasi yang lebihbaikdengantimsupervisi.

d. Guru terus meningkatkan kemampuan dan keterampilan dalam penguasaan teknologi yang menunjang kinerja.

3. PenelitiSelanjutnya

Penelitian ini hanya memfokuskan penelitian tentang pelaksanaan manajemen supervise klinis pada satu sekolah, terutama untuk melihat peran supervise klinis untuk meningkatkan profesionalisme guru. Disarankan agar peneliti berikutnya dapat melakukan penelitian di beberapasekolah tentang pelaksanaan manajemen supervise klinis.

\section{Daftar Pustaka}

Barinto,(2012), Jurnal Tabularasa PPs UNIMED Vol.9 No.2;

Dokumen Kursus Kepemimpinan Sekolah, (2009),Supervisi Di Sekolah, Yogyakarta;

Kunandar, (2004), Guru Profesional: Implementasi Kurikulum Tingkat Satuan Pendidikan dan Sukses Dalam Sertifikasi Guru, Raja Grafindo, Jakarta;

Majelis Luhur Persatuan Tamansiswa, (2013), Ki Hadjar Dewantara: Pemikiran, Konsepsi, Keteladanan, Sikap Merdeka (Pendidikan), UST Press, Yogyakarta;

http://dirgantara.blogdetik.com. 